\title{
Quality Assurance for Patients with Breast Cancer - the Impact of Clinical Cancer Registries
}

\author{
Versorgungsqualität von Patientinnen mit Mammakarzinom - \\ die Bedeutung der klinischen Krebsregister
}

Authors

Affiliations

\section{E. C. Inwald ${ }^{1}$, M. Klinkhammer-Schalke ${ }^{2}$, M. Koller ${ }^{3}$, O. Ortmann ${ }^{1}$}

1 Department of Gynecology and Obstetrics, University Medical Center Regensburg, Regensburg

2 University of Regensburg, Tumor Center Regensburg e. V., Regensburg

${ }^{3}$ University Hospital Regensburg, Center for Clinical Studies, Regensburg

\section{Key words \\ - breast cancer \\ - cancer registry \\ - quality assurance \\ Schlüsselwörter \\ - Mammakarzinom \\ - Krebsregister \\ - Qualitätssicherung}

received 15.7.2014 revised 11.8.2014 accepted 12.8.2014

\section{Bibliography}

DOI http://dx.doi.org/ 10.1055/s-0034-1383052 Geburtsh Frauenheilk 2014; 74 : 868-874 @ Georg Thieme Verlag KG Stuttgart - New York . ISSN 0016-5751

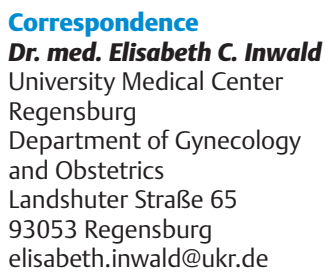

\section{Abstract \\ $\nabla$}

Introduction: Since 2000 all service providers in the German healthcare system are legally obliged to take part in quality assurance $(\mathrm{QA})$ procedures as stipulated in Book Five of the German Social Code. Clinical cancer registries provide methodological tools to assess the quality of structures, processes and outcomes. The aim of this study was to analyze the consequences of guidelineconcordant treatment using two examples of quality indicators: endocrine therapy (adjuvant hormonal therapy, AHT) to treat patients with steroid hormone receptor (SHR)-positive breast cancer and trastuzumab therapy to treat patients with HER2-positive breast cancer.

Material and Methods: Data from the Tumor Center Regensburg (Bavaria, Germany) included all female patients listed in the registry with primary, non-metastatic invasive breast cancer diagnosed between 2000 and 2012 .

Results: A total of 6164 patients with invasive breast cancer and known HER2 status were analyzed. 1134 patients (18.4\%) had HER2-positive and 5346 patients $(86.7 \%$ ) had SHR-positive breast cancer. Premenopausal patients with HER2-positive breast cancer receiving trastuzumab had a 7-year OS rate of $93.8 \%$ compared to $86.8 \%$ of patients who did not receive trastuzumab $(p=0.079)$. Similarly, postmenopausal patients with HER2-positive breast cancer treated with trastuzumab had better 7-year OS rates (87.3\%) than patients who did not receive the antibody (76.7\%) ( $\mathrm{p}<0.001)$. Premenopausal patients with SHR-positive breast cancer receiving AHT had a 7-year OS rate of $95.2 \%$ compared to $75.9 \%$ of patients who did not receive AHT $(\mathrm{p}<0.001)$. Equally, postmenopausal patients treated with AHT had a 7-year OS rate of $83.8 \%$ compared to $64.1 \%$ without AHT ( $<<0.001)$.

Conclusion: Clinical cancer registries depend on the cooperation of the various health service pro-

\section{Zusammenfassung \\ $\boldsymbol{\nabla}$}

Einleitung: Gemäß dem Sozialgesetzbuch V sind seit dem Jahr 2000 alle Leistungserbringer im deutschen Gesundheitssystem zu Qualitätssicherungsmaßnahmen verpflichtet. Klinische Krebsregister erfassen sektorenübergreifend Daten zur Prozess-, Struktur- und Ergebnisqualität. Ziel dieser Studie war die Analyse der Konsequenzen einer leitliniengerechten Therapie anhand von 2 Beispielen von Qualitätsindikatoren: endokrine Therapie (AHT) beim Steroidhormonrezeptor(SHR-)positiven und Trastuzumab-Therapie beim HER2-positiven Mammakarzinom.

Material und Methodik: Ausgewertet wurden Daten von Patientinnen des bevölkerungsbezogenen klinischen Krebsregisters Regensburg (Bayern, Deutschland) mit einem primären, nicht metastasierten Mammakarzinom (Diagnosezeitraum 2000-2012).

Ergebnisse: 6164 Brustkrebspatientinnen, bei denen der HER2-Status bekannt war, wurden analysiert. 1134 Patientinnen (18,4\%) hatten ein HER2-positives und 5346 Patientinnen (86,7\%) ein SHR-positives Mammakarzinom. Prämenopausale Patientinnen mit einem HER2-positiven Mammakarzinom, die Trastuzumab erhielten, hatten eine 7-Jahres-Überlebensrate (ÜR) von $93,8 \%$ verglichen mit $86,8 \%$ bei Patientinnen, die kein Trastuzumab erhielten $(p=0,079)$. Postmenopausale Patientinnen mit TrastuzumabTherapie hatten analog bessere 7-Jahres-ÜR (87,3\%) als diejenigen Patientinnen ohne Trastuzumab-Therapie $(76,7 \%)$ ( $p<0,001)$. Prämenopausale Patientinnen mit SHR-positivem Brustkrebs mit AHT hatten 7-Jahres-ÜR von 95,2\% verglichen mit $75,9 \%$ bei Patientinnen ohne AHT $(p<0,001)$. Ebenso hatten postmenopausale Patientinnen mit AHT 7-Jahres-ÜR von 83,8\% verglichen mit $64,1 \%$ ohne AHT ( $p<0,001$ ).

Schlussfolgerung: Ein funktionsfähiges klinisches Krebsregister beruht auf Kooperation der 
viders to generate data that are essential for QA for breast cancer patients. verschiedenen Leistungserbringer im Gesundheitssystem und liefert Daten, die essenziell für die Qualitätssicherung von Brustkrebspatientinnen sind.

\section{Introduction}

Since 2000 all service providers in the German healthcare system are legally obliged to take part in quality assurance (QA) procedures as stipulated in Book Five of the German Social Code (SGB V) [1]. Currently, QA procedures are only being implemented in in-patient care. The Federal Joint Committee (Gemeinsamer Bundesausschuss, G-BA) consists of all relevant stakeholders of the German healthcare system. The G-BA is a common platform; it is the highest decision-making authority and sets the standards for QA in healthcare services in Germany [2]. In 2009, the G-BA commissioned the Institute for Applied Quality Improvement and Research in Health Care (AQUA) to implement a nationwide cross-sectoral healthcare QA program. The AQUA Institute is an independent and impartial body that provides QA services [3]. Structured treatment programs, also known as Disease Management Programs (DMP), created by the Association of Statutory Health Insurance Physicians (Kassenärztliche Bundesvereinigung - KBV) have also been implemented as an attempt to improve patient care [4]. Since 2013 clinical cancer registries in Germany have been collecting the data of all oncological diseases from all sectors and processes in accordance with SGB V § 65c.

\section{Types of QA}

Book Five of the German Social Code ( $\$ 137$ a SGB V) lists three approaches for QA: assessment of process quality, structural quality, or outcome quality [1]. This quality-of-care framework is based on the work of Avedis Donabedian [5].

- Process quality refers to the way how output is achieved. It includes all medical, custodial and administrative services that are involved, directly or indirectly, in the immediate provision of healthcare services. Process quality looks at the implementation of standards and guidelines such as the German interdisciplinary S3 Guidelines for Diagnosis, Treatment and Follow-up Care of Breast Cancer (updated version 07/2012, register number 032-0450L of the Association of Scientific Medical Societies, AWMF) [6] or the S3 Guideline on Diagnostics, Therapy and Follow-up of Malignant Ovarian Tumors (updated version 06/2013, register number 032/0350L) [7].

- Structural quality focuses on the general framework of medical care, for example, the establishment of certified breast cancer centers [8]. It focuses both on human resources including skills, competence and staff qualifications and on material resources such as infrastructure and equipment. Organizational and financial resources are also included.

- Outcome quality is defined as the extent to which objectives are achieved and target agreements are complied with, which serve as indicators of the quality of results. This means changes in the current and future status of patients' health which are attributable to medical and administrative practices, e.g. changes in mortality and survival rates [9].

All three quality dimensions interact with and influence each other. Structures act on processes; these determine the quality of outcomes, which in turn lead to changes in the scheduling of processes and structures.

The quality in different sectors is measured. Measurement is done using quality indicators (QIs) defined in various guidelines
[10]. The QIs in guidelines serve as the basis for the definitions of the QIs used by AQUA and DMP. The AQUA Institute measures QIs in in-patient care. DMPs monitor QIs in in-patient and outpatient care. In addition to QIs extrapolated from specific guidelines, QA as implemented by the optional framework of certified cancer centers also serves to monitor structural QIs and assess the functionality of networks.

\section{Impact and tasks of clinical cancer registries}

However, the evaluation of outcome quality is difficult as it cannot be measured independently. Certified breast and gynecological cancer centers try to obtain information about follow-up care, but data collection is time-consuming, expensive, and often incomplete. Moreover, the flow of information is neither continuous nor independent.

Clinical cancer registries are a solution to these problems. Clinical cancer registries are professional independent facilities that record all important data collected in the course of cancer diagnosis and treatment [11]. Following a stringent protocol, clinical cancer registries offer a cross-sectoral documentation of breast cancer, gynecological cancers, and all major cancers for a population in a defined area. Information on diagnosis, course of disease, treatment, follow-up, recurrence, survival, and death are documented. All service providers involved in the care of cancer patients are obliged to transfer data to the clinical cancer registries. Using medical reports, pathology and follow-up records, these population-based data are routinely documented and fed into the registry [12]. Such a comprehensive data pool makes it possible to analyse the structures of patient-centered care. Consequently, clinical cancer registries are at the heart of QA for cancer patients' care [13].

The German law on cancer screening and QA created the judicial and financial framework for the establishment of clinical cancer registries (Law on the Continued Development of Early Cancer Detection and Quality Assurance Through Clinical Cancer Registries, KFRG SGB V) [14]. Uniform and efficient data collection is essential, and this is also one of the objectives of the National Cancer Plan [15].

Another key aspect of clinical cancer registries is passing on data from the follow-up of cancer patients and on survival rates to healthcare providers. Regular data analysis including benchmarking can reveal general or local deficits which may indicate a need for revision and provide a basis for suitable measures to improve patient care. For example, sentinel lymph node biopsy (SLNB) has become the standard of care for breast cancer patients with clinically negative axilla. SLNB was demonstrated to be equivalent to axillary dissection in terms of local control in SLNnegative patients [16]. Moreover, patient morbidity after SLNB is significantly lower compared to axillary dissection, resulting in a better quality of life [6].

In the present study we examined two QIs in breast cancer that are documented by clinical cancer registries: endocrine therapy in patients with steroid hormone receptor (SHR)-positive cancer and trastuzumab administration in patients with HER2-positive breast cancer [17]. The objective of these QIs is defined as providing endocrine therapy (AHT) to as many SHR-positive breast cancer patients as possible and providing one year of trastuzumab 
Table 1 Association between HER2 status and clinical and histopathological parameters.

\begin{tabular}{|c|c|c|c|c|}
\hline Parameter & $\begin{array}{l}\text { HER2-negative } \\
(\mathrm{n}=5030)\end{array}$ & $\begin{array}{l}\text { HER2-positive } \\
(n=1134)\end{array}$ & $\begin{array}{l}\text { Total HER2 } \\
(n=6164)\end{array}$ & p-value ${ }^{a}$ \\
\hline Age (y), mean \pm SD & $62 \pm 13$ & $60 \pm 13$ & $61 \pm 13$ & $<0.001$ \\
\hline \multicolumn{5}{|c|}{ Menopausal state, n (\%) } \\
\hline Premenopausal & $1082(21.5 \%)$ & $305(26.9 \%)$ & 1387 (22.5\%) & $<0.001$ \\
\hline Postmenopausal & $3948(78.5 \%)$ & $829(73.1 \%)$ & $4777(77.5 \%)$ & \\
\hline \multicolumn{5}{|l|}{ Histology, n (\%) } \\
\hline Ductal & $3970(78.9 \%)$ & $986(86.9 \%)$ & $4956(80.4 \%)$ & $<0.001$ \\
\hline Lobular & $685(13.6 \%)$ & $92(8.1 \%)$ & $777(12.6 \%)$ & \\
\hline Other & $375(7.5 \%)$ & $56(4.9 \%)$ & $431(7.0 \%)$ & \\
\hline \multicolumn{5}{|l|}{ Tumor size, n (\%) } \\
\hline pT1 & $2804(55.7 \%)$ & $553(48.8 \%)$ & 3357 (54.5\%) & $<0.001$ \\
\hline pT2 & $1803(35.8 \%)$ & $477(42.1 \%)$ & $2280(37.0 \%)$ & \\
\hline pT3 & $190(3.8 \%)$ & $47(4.1 \%)$ & $237(3.8 \%)$ & \\
\hline pT4 & $215(4.3 \%)$ & $52(4.6 \%)$ & $267(4.3 \%)$ & \\
\hline Unknown & $18(0.4 \%)$ & $5(0.4 \%)$ & $23(0.4 \%)$ & \\
\hline \multicolumn{5}{|l|}{ Nodal status, $\mathbf{n}(\%)$} \\
\hline pNO & $3217(64.0 \%)$ & $628(55.4 \%)$ & $3845(62.4 \%)$ & $<0.001$ \\
\hline pN1 & $1182(23.5 \%)$ & $281(24.8 \%)$ & $1463(23.7 \%)$ & \\
\hline pN2 & $323(6.4 \%)$ & $111(9.8 \%)$ & $434(7.0 \%)$ & \\
\hline pN3 & $217(4.3 \%)$ & $93(8.2 \%)$ & $310(5.0 \%)$ & \\
\hline Unknown & $91(1.8 \%)$ & $21(1.9 \%)$ & $112(1.8 \%)$ & \\
\hline \multicolumn{5}{|l|}{ Grading, n (\%) } \\
\hline G1 & $877(17.4 \%)$ & $70(6.2 \%)$ & $947(15.4 \%)$ & $<0.001$ \\
\hline G2 & $3025(60.1 \%)$ & $560(49.4 \%)$ & $3585(58.2 \%)$ & \\
\hline G3 & $1110(22.1 \%)$ & $500(44.1 \%)$ & $1610(26.1 \%)$ & \\
\hline Unknown & $18(0.4 \%)$ & $4(0.4 \%)$ & $22(0.4 \%)$ & \\
\hline \multicolumn{5}{|c|}{ Estrogen receptor, $\mathrm{n}(\%)$} \\
\hline Positive & $4419(87.9 \%)$ & $835(73.6 \%)$ & $5254(85.2 \%)$ & $<0.001$ \\
\hline Negative & $609(12.1 \%)$ & $297(26.2 \%)$ & $906(14.7 \%)$ & \\
\hline Unknown & $2(<0.1 \%)$ & $2(0.2 \%)$ & $4(0.1 \%)$ & \\
\hline \multicolumn{5}{|c|}{ Progesterone receptor, $\mathbf{n}$ (\%) } \\
\hline Positive & $4054(80.6 \%)$ & $693(61.1 \%)$ & $4747(77.0 \%)$ & $<0.001$ \\
\hline Negative & $974(19.4 \%)$ & $439(38.7 \%)$ & $1413(22.9 \%)$ & \\
\hline Unknown & $2(<0.1 \%)$ & $2(0.2 \%)$ & $4(0.1 \%)$ & \\
\hline \multicolumn{5}{|l|}{ Receptor status, n (\%) } \\
\hline$E R+P R+$ & $3982(79.2 \%)$ & $666(58.7 \%)$ & $4648(75.4 \%)$ & $<0.001$ \\
\hline$E R+P R-$ & $434(8.6 \%)$ & $168(14.8 \%)$ & $602(9.8 \%)$ & \\
\hline ER-PR+ & $70(1.4 \%)$ & $26(2.3 \%)$ & $96(1.6 \%)$ & \\
\hline ER-PR- & $539(10.7 \%)$ & $271(23.9 \%)$ & $810(13.1 \%)$ & \\
\hline Unknown & $5(0.1 \%)$ & $3(0.3 \%)$ & $8(0.1 \%)$ & \\
\hline \multicolumn{5}{|c|}{ Lymphatic invasion, $\mathbf{n}(\%)$} \\
\hline Positive & $1336(26.6 \%)$ & $430(37.9 \%)$ & $1766(28.7 \%)$ & $<0.001$ \\
\hline Negative & $2652(52.7 \%)$ & $435(38.4 \%)$ & $3087(50.1 \%)$ & \\
\hline Unknown & $1042(20.7 \%)$ & $269(23.7 \%)$ & $1311(21.3 \%)$ & \\
\hline \multicolumn{5}{|c|}{ Vascular invasion, $\mathbf{n}(\%)$} \\
\hline Positive & $260(5.2 \%)$ & $96(8.5 \%)$ & $356(5.8 \%)$ & $<0.001$ \\
\hline Negative & $3588(71.3 \%)$ & $719(63.4 \%)$ & $4307(69.9 \%)$ & \\
\hline Unknown & $1182(23.5 \%)$ & $319(28.1 \%)$ & $1501(24.4 \%)$ & \\
\hline \multicolumn{5}{|c|}{ Ki-67 categories (\%), n (\%) } \\
\hline $0-15$ & $2303(45.8 \%)$ & $269(23.7 \%)$ & $2572(41.7 \%)$ & $<0.001$ \\
\hline $16-25$ & $661(13.1 \%)$ & $177(15.6 \%)$ & $838(13.6 \%)$ & \\
\hline $26-35$ & $308(6.1 \%)$ & $138(12.2 \%)$ & $446(7.2 \%)$ & \\
\hline $36-45$ & $127(2.5 \%)$ & $83(7.3 \%)$ & $210(3.4 \%)$ & \\
\hline$>45$ & $318(6.3 \%)$ & $108(9.5 \%)$ & $426(6.9 \%)$ & \\
\hline Unknown & $1313(26.1 \%)$ & $359(31.7 \%)$ & $1672(27.1 \%)$ & \\
\hline
\end{tabular}

a p-value calculated with t-test or Pearson's chi-squared test, respectively 
Table 2 OS rates categorized by menopausal status and trastuzumab therapy in patients with HER2-positive breast cancer.

\begin{tabular}{|llllllrc|}
\hline Menopausal status & Trastuzumab & 3-year OS & 5-year OS & 7-year OS & Numbers at risk & Cumulative events \\
Premenopausal & received & $96.6 \%$ & $96.6 \%$ & $93.8 \%$ & 133 & 5 \\
\hline & not received & $95.0 \%$ & $91.5 \%$ & $86.8 \%$ & 172 & 22 \\
\hline Postmenopausal & received & $95.6 \%$ & $90.8 \%$ & $87.3 \%$ & 256 & 20 \\
\hline & not received & $87.2 \%$ & $81.1 \%$ & $76.7 \%$ & 573 & 134 \\
\hline
\end{tabular}

therapy to as many patients with HER2-positive breast cancer as possible. The aim of this study was to analyze the effects of the (non-)fulfillment of QIs.

\section{Material and Methods \\ $\nabla$}

\section{Database}

Data were obtained from the Tumor Center Regensburg (Bavaria, Germany), a population-based regional cancer registry covering a population of more than 2.2 million people in the Upper Palatinate and Lower Bavaria. The Clinical Cancer Registry Regensburg was established in 1991 and currently has data on the follow-up of almost 250000 patients. Patient data were collected from 53 regional hospitals, the University Hospital Regensburg, and more than 1000 doctors in private practice. Mortality data were obtained from all regional registry offices [18].

In Bavaria, the law on the Bavarian Epidemiological Cancer Registry (Gesetz über das bevölkerungsbezogene Krebsregister Bayern $B a y K R G$, regularly amended) ensures that data acquisition is continuous and carried out according to standard procedures by an epidemiological cancer registry. The aim of the law is to regulate cancer control and improve the quality of data on cancer epidemiology. The Bavarian Epidemiological Cancer Registry is legally obliged to provide anonymous data for scientific studies. Informed consent is given in accordance with the Declaration of Helsinki and is indispensable for data storage. Every physician must inform patients about the intended or implemented transmission of data to the registry. Patients also receive written information about these procedures. Every patient has the right to object to the storage of his or her data at any time.

\section{Inclusion and exclusion criteria}

The present analysis included all female patients in the registry with primary, non-metastatic (M0) invasive breast cancer diagnosed between January 2000 and December 2012 (13 years). Patients were followed-up until May 2013. Exclusion criteria were male gender, ductal carcinoma in situ (DCIS), neoadjuvant treatment, and distant metastasis at primary diagnosis or in the course of disease.

\section{Statistical methods}

This analysis examined the impact of guideline-concordant treatment on survival. These results have not been published elsewhere, although other papers from this working group have highlighted other aspects of the data set.

Continuous data are expressed as means \pm standard deviation (SD) and categorical data as frequency counts (percentages). Baseline characteristics of patients were compared for HER2 status by Student's t-test for continuous variables and by Pearson's $\mathrm{X}^{2}$ tests for categorical variables. Overall survival (OS) was calculated from the date of cancer diagnosis to the date of death from any cause. Patients who are not dead and patients without fol- low-up were classified as censored. Kaplan-Meier plots were used to illustrate survival. All reported p-values are two-sided, and a p-value of 0.05 was considered the threshold for statistical significance. Calculations were done using the software package SPSS 21.0.0.1 (Chicago, IL, USA).

\section{Results}

\section{Patient cohort}

Data for a total of 6164 patients with invasive breast cancer according to the ICD-10 classification (C50) and with known HER2 status were extracted for statistical analysis. Of these patients, 1387 patients $(22.5 \%)$ were premenopausal and 4777 patients (77.5\%) were postmenopausal.

5030 patients $(81.6 \%)$ had HER2-negative disease, and 1134 patients (18.4\%) had HER2-positive (overexpression and/or amplification) breast cancer. Detailed information on patient characteristics and histopathology according to HER2 status are presented in $\bigcirc$ Table 1. Statistically significant differences between HER2positive and HER2-negative patients were found for all tested parameters ( $\mathrm{p}<0.001) .5346$ patients $(86.7 \%)$ had SHR-positive breast cancer, i.e., estrogen receptor (ER) and/or progesterone receptor (PR) positive disease. Of these patients, 1147 patients (21.5\%) were premenopausal and 4199 patients (78.5\%) were postmenopausal. A detailed description of the analysis of HER2 expression was given in a previous study published by our group [18].

\section{Trastuzumab therapy in patients} with HER2-positive breast cancer Overall, only $43.6 \%(n=133 / 305)$ of premenopausal and $30.9 \%$ $(n=256 / 829)$ of postmenopausal patients with HER2-positive breast cancer received trastuzumab. Since trastuzumab was approved for adjuvant therapy in 2006, the number of patients with HER2-positive breast cancer receiving the antibody has risen continuously. The percentage of premenopausal patients receiving trastuzumab therapy increased from 58\% in 2006 to $91 \%$ in 2011. In contrast, the rate for postmenopausal patients receiving trastuzumab has remained almost constant at around 50\% [18]. Guideline-concordant therapy has resulted in improved survival rates for both pre- and postmenopausal patients ( $\bullet$ Figs. 1 a and b). Premenopausal patients with HER2-positive breast cancer receiving trastuzumab had a 7-year overall survival (OS) rate of $93.8 \%$ compared to $86.8 \%$ for patients who did not receive trastuzumab ( $\mathrm{p}=0.079)$ ( Table 2). Similarly, postmenopausal HER2-positive patients treated with trastuzumab had better 7year OS rates $(87.3 \%)$ than patients who did not receive the antibody $(76.7 \%)(\mathrm{p}<0.001)$.

\section{AHT in patients with SHR-positive breast cancer}

More than $85.0 \%$ patients with SHR-positive breast cancer, some premenopausal $(86.1 \%, \mathrm{n}=988 / 1147)$ and some postmenopausal 


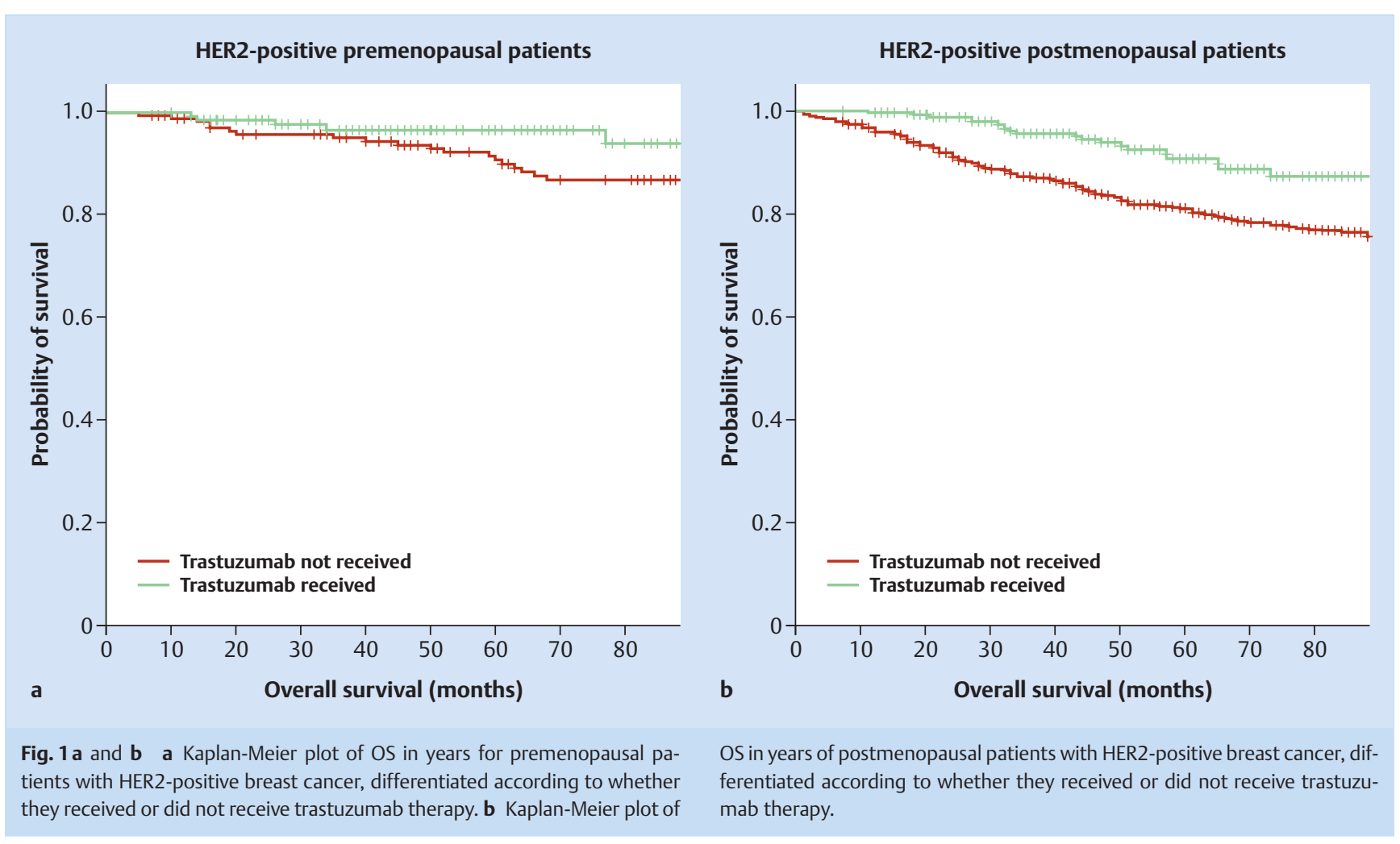

Table 3 OS rates categorized by menopausal status and AHT in patients with SHR-positive breast cancer.

\begin{tabular}{|lllllcr|r|}
\hline Menopausal status & AHT & 3-year OS & 5-year OS & 7-year OS & Numbers at risk & Cumulative events \\
Premenopausal & received & $98.6 \%$ & $97.3 \%$ & $95.2 \%$ & \multicolumn{1}{c}{988} & 46 \\
\hline & not received & $93.3 \%$ & $89.6 \%$ & $75.9 \%$ & 159 & 19 \\
\hline Postmenopausal & received & $95.0 \%$ & $89.2 \%$ & $83.8 \%$ & 3578 & 494 \\
\hline & not received & $79.7 \%$ & $71.8 \%$ & $64.1 \%$ & 621 & 165 \\
\hline
\end{tabular}

(85.2\%, $\mathrm{n}=3578 / 4199)$, received AHT. Here too, guideline-concordant therapy resulted in better survival rates ( $\square$ Table 3 ). Premenopausal patients who were SHR-positive and received AHT had a 7 -year OS rate of $95.2 \%$ compared to $75.9 \%$ of patients who did not receive AHT ( $p<0.001$ ) ( Fig. 2 a). Equally, postmenopausal patients treated with AHT had a 7-year OS rate of $83.8 \%$ compared to $64.1 \%$ for patients who did not receive AHT $(\mathrm{p}<0.001)(\odot$ Fig. 2 b).

\section{Discussion \\ $\nabla$}

Using data from a population-based regional cancer registry we were able to analyze guideline-concordant patient care in routine clinical practice. Guideline-concordant treatment led to higher OS, both for patients with HER2-positive and patients with SHRpositive breast cancer. Nevertheless, a considerable number of patients with HER2-positive breast cancer did not receive adequate treatment. Similar to our results, a cohort study by the National Comprehensive Cancer Network (NCCN) demonstrated that, overall, only $44 \%$ of patients with HER2-positive breast cancer received neoadjuvant or adjuvant trastuzumab, although the proportion of patients receiving trastuzumab increased over time [19]. However, guideline-concordant therapy was shown to be correlated with improved survival rates in previous studies, which is also in accordance with our results $[20,21]$. In our study, more than $85.0 \%$ of patients with SHR-positive breast cancer, both premenopausal and postmenopausal, received AHT. This finding is comparable to previous findings in a study on breast cancer patients: $11 \%$ of patients never initiated therapy and $15 \%$ discontinued treatment prematurely [22]. However, low adherence to AHT treatment is associated with a higher risk of mortality [23].

Book Five of the German Social Code mandates three types of QA for cancer patients through the assessment of process, structural, and outcome quality [1]. There are a number of distinct and defined measures which can be used to improve process quality and structural quality, for example, by implementing guidelines or establishing certified breast cancer centers. Nevertheless, there are still some deficits with regard to the objective evaluation of outcome quality which can be handled with the help of clinical cancer registries. The main task of clinical cancer registries is the analysis of submitted data and the subsequent feedback of results to healthcare providers. The findings from clinical cancer registries are important for quality control, for example, information on adherence to guidelines. Moreover, the insights obtained with 


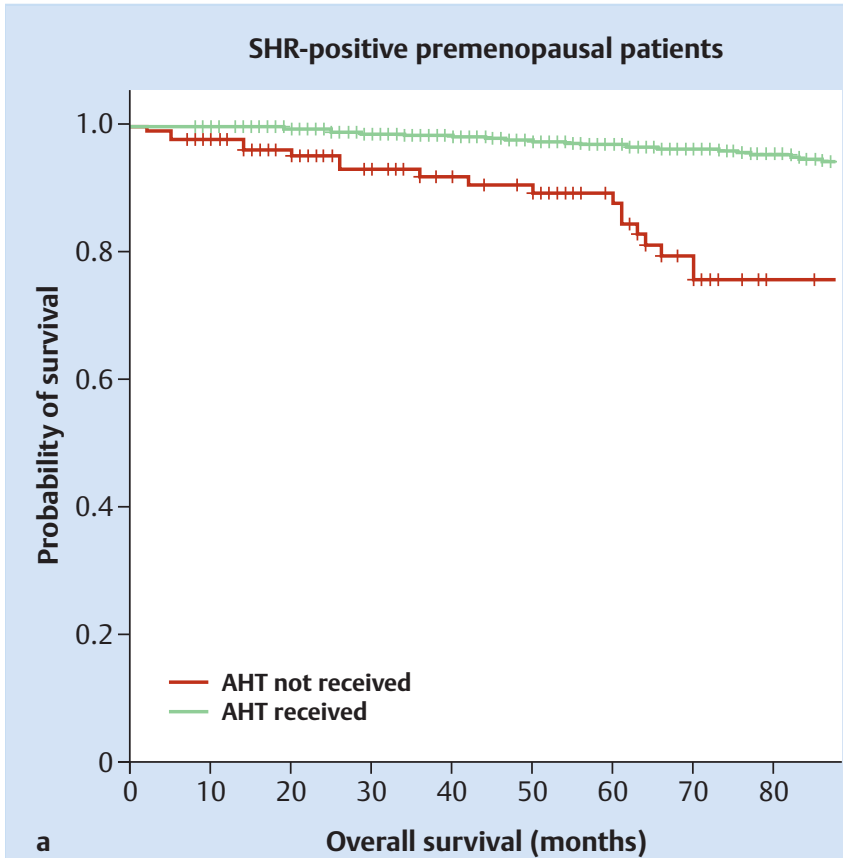

Fig. $\mathbf{2} \mathbf{a}$ and $\mathbf{b}$ a Kaplan-Meier plot of OS in years of premenopausal patients with SHR-positive breast cancer, differentiated according to whether they received or did not receive AHT. b Kaplan-Meier plot of OS in years of

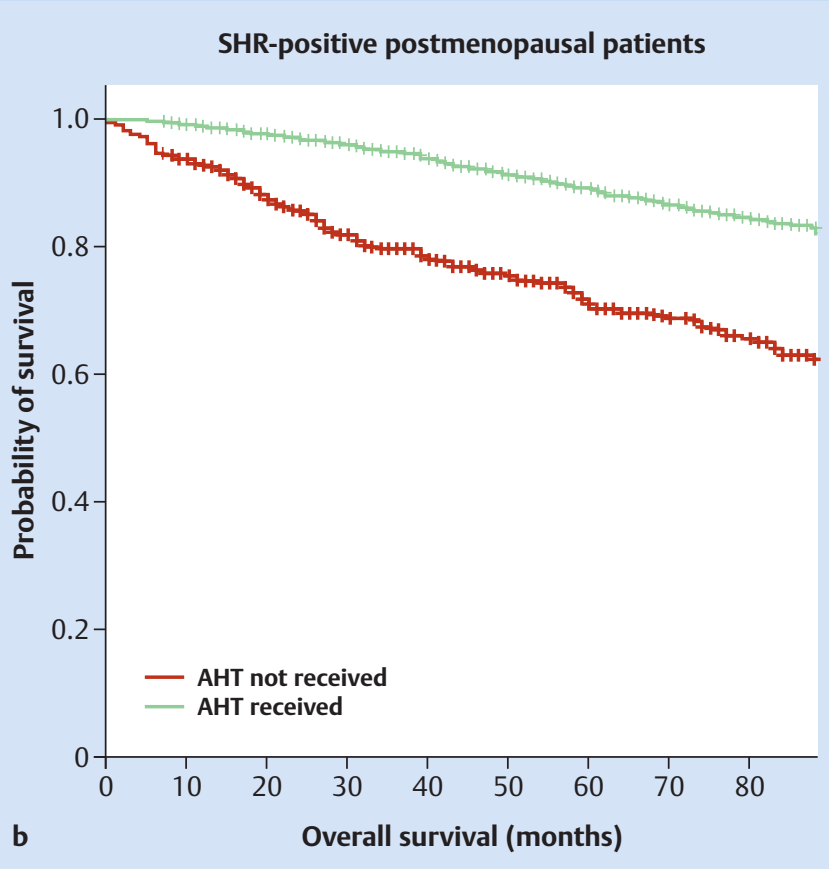

postmenopausal patients with SHR-positive breast cancer, differentiated according to whether they received or did not receive AHT. this information make it possible to compare the quality of different treatment facilities and detect unjustifiable differences in quality between facilities. This can then be used to implement procedures to improve quality. Clinical cancer registries compile and analyze standardized cross-sectoral information on the diagnosis, treatment, and follow-up of malignant cancers. By compiling and analyzing this data, all three aspects of QA are documented: process quality (e.g., adherence to standards of treatment), structural quality, and outcome quality (e.g., overall survival and disease-free survival).

Using the data on diagnosis, treatment, and follow-up provided by clinical cancer registries, the success of QA procedures (e.g., compliance with QIs) can be monitored. Based on the analysis of two QIs for breast cancer patients we were able to demonstrate the consequences of guideline-concordant therapy. Current state of the art for patients with SHR-positive breast cancer is AHT for at least five years $[6,24,25]$. However, data from clinical cancer registries show that AHT is often terminated before the end of five years [22]. Simultaneously, these data also show that nonadministration or inadequate administration of adjuvant hormone therapy results in lower survival rates. These findings reinforce the importance of complying strictly with guidelines. One limitation of a study which uses patient data from populationbased cancer registries could be that this data primarily covers subnational or regional districts and does not reflect the entire population. The regional data might not be representative of national data due to regional variances such as risk factors or access to early screening. However, the strength of the data is that it reflects routine healthcare provisions. Consequently, these data can be used to analyze the structures of patient-centered care.

\section{Conclusion}

Cancer registries are important as they provide vital information for the evaluation of healthcare services and QA for breast cancer patients. All cancer patients should therefore be reported to a cancer registry, and data should include relevant information on diagnosis and therapy. With their population-based and regional analyses of long-term follow-up, cancer registries contribute to QA. An essential precondition for a functioning clinical cancer center is the cooperation of the different health service providers who transfer patient data to the clinical cancer registries.

\section{Conflict of Interest \\ $\nabla$}

The authors declare that they have no conflict of interests.

\section{References}

1 Sozialgesetzbuch V. Online: http://www.sozialgesetzbuch-sgb.de/ sgbv/137a.html; last access: 13.07.2014

2 Gemeinsamer Bundesausschuss Online: https://www.g-ba.de/ institution/aufgabe/; last access: 13.07.2014

3 Aqua Institut. Online: http://www.aqua-institut.de/de/projekte/137asgb-v/index.html; last access: 13.07.2014

4 Kassenärztliche Bundesvereinigung. Online: http://www.kbv.de/html/ dmp.php; last access: 13.07.2014

5 Donabedian A. Evaluating the quality of medical care. 1966. Milbank Q 2005; 83: 691-729

6 Kreienberg $R$, Albert $U$, Follmann $M$ et al. Interdisciplinary GoR level III guidelines for the diagnosis, therapy and follow-up care of breast cancer: short version - AWMF Registry No.: 032-045OL. Geburtsh Frauenheilk 2013; 73: 556-583 
7 Wagner U, Harter P, Hilpert F et al. S3-guideline on diagnostics, therapy and follow-up of malignant ovarian tumours: short version 1.0 AWMF registration number: 032/0350L, June 2013. Geburtsh Frauenheilk 2013; 73: 874-889

8 Lux M, Hildebrandt T, Beyer-Finkler E et al. Relevance of health economics in breast cancer treatment - the view of certified breast centres and their patients. Breast Care (Basel) 2013; 8: 15-21

9 Beckmann MW, Brucker C, Hanf V et al. Quality assured health care in certified breast centers and improvement of the prognosis of breast cancer patients. Onkologie 2011; 34: 362-367

10 Wesselmann S, Beckmann MW, Winter A. The concept of the certification system of the German Cancer Society and its impact on gynecological cancer care. Arch Gynecol Obstet 2014; 289: 7-12

11 Klinkhammer-Schalke M, Marschner N, Hofstädter F. Register in der onkologischen Versorgungsforschung. Onkologe 2012; 18: 142-150

12 Inwald EC, Klinkhammer-Schalke M, Hofstädter F et al. Ki-67 is a prognostic parameter in breast cancer patients: results of a large population-based cohort of a cancer registry. Breast Cancer Res Treat 2013; 139: 539-552

13 Hofstädter F, Klinkhammer-Schalke M. Aufgaben und Strukturen für die klinische Krebsregistrierung. Onkologe 2011; 17: 121-125

14 Bundesgesetzblatt, Krebsfrüherkennung und -registergesetz. Online: http://www.bgbl.de/banzxaver/bgbl/start.xav\#_bgbl_\%2F\%2F*[\%40 attr_id\%3D\%27bgbl113s0617.pdf\%27]_1405247733835; last access: 13.07.2014

15 Bundesministerium für Gesundheit. Nationaler Lehrplan. Online: https://www.bundesgesundheitsministerium.de/fileadmin/dateien/ Publikationen/Praevention/Broschueren/Broschuere_Nationaler_ Krebsplan_-_Handlungsfelder_Ziele_und_Umsetzungsempfehlungen. pdf; last access: 13.07.2014

16 Glechner A, Wöckel A, Gartlehner G et al. Sentinel lymph node dissection only versus complete axillary lymph node dissection in early invasive breast cancer: a systematic review and meta-analysis. Eur J Cancer 2013; 49: 812-825
17 Deutsche Krebsgesellschaft (DKG). Kennzahlenbogen Brust. Online: http://www.medizin-management-verband.de/pdf/medizinmanagement-preis-2013/D_Dt.Krebsgesellschaft_Anlage3.pdf; last access: 13.07 .2014

18 Inwald EC, Ortmann O, Zeman F et al. Guideline concordant therapy prolongs survival in HER2-positive breast cancer patients: results from a large population-based cohort of a cancer registry. Biomed Res Int 2014; 2014: 137304

19 Vaz-Luis I, Ottesen RA, Hughes ME et al. Impact of hormone receptor status on patterns of recurrence and clinical outcomes among patients with human epidermal growth factor-2-positive breast cancer in the National Comprehensive Cancer Network: a prospective cohort study. Breast Cancer Research 2012; 14: R129

20 Dawood S, Broglio K, Buzdar AU et al. Prognosis of women with metastatic breast cancer by HER2 status and trastuzumab treatment: an institutional-based review. J Clin Oncol 2010; 28: 92-98

21 Seal MD, Speers CH, O'Reilly $S$ et al. Outcomes of women with earlystage breast cancer receiving adjuvant trastuzumab. Curr Oncol 2012; 19: 197-201

22 Friese CR, Pini TM, Li Y et al. Adjuvant endocrine therapy initiation and persistence in a diverse sample of patients with breast cancer. Breast Cancer Res Treat 2013; 138: 931-939

23 Makubate B, Donnan PT, Dewar JA et al. Cohort study of adherence to adjuvant endocrine therapy, breast cancer recurrence and mortality. Br J Cancer 2013; 108: 1515-1524

24 Untch M, Gerber B, Harbeck $N$ et al. 13th St. Gallen international breast cancer conference 2013: primary therapy of early breast cancer evidence, controversies, consensus - opinion of a German team of experts (Zurich 2013). Breast Care (Basel) 2013; 8: 221-229

25 Lux M, Maass N, Schütz F et al. Breast cancer 2013 - interpretation of new and known data. Geburtsh Frauenheilk 2013; 73: 584-598 